\title{
DESEMPENHO FÍSICO-QUÍMICO E MECÂNICO DE CONCRETO DE CIMENTO PORTLAND COM BORRACHA DE ESTIRENO-BUTADIENO RECICLADA DE PNEUS
}

\author{
Camila Freitas e José Carlos Alves Galvão \\ Departamento de Engenharia, Universidade Federal do Paraná, CP 19011, 81531-990 Curitiba - PR, Brasil
}

Kleber Franke Portella* e Alex Joukoski

Departamento de Tecnologia em Materiais, Instituto de Tecnologia para o Desenvolvimento, CP 19067, 81531-980 Curitiba - PR, Brasil

\section{Carlos Vicente Gomes Filho}

Instituto de Engenharia do Paraná, R. Emiliano Perneta, 174, 80010-050 Curitiba - PR, Brasil

Elizeu Santos Ferreira

Departamento de Manutenção da Geração, Companhia Paranaense de Energia, R. José Izidoro Biazetto, 158, 81200-240

Curitiba - PR, Brasil

Recebido em 23/4/08; aceito em 13/10/08; publicado na web em 26/1/09

\begin{abstract}
PHYSICOCHEMICAL AND MECHANICAL PERFORMANCE OF PORTLAND CEMENT CONCRETE WITH RECYCLED STYRENE-BUTADIENE TYRE-RUBBER WASTE. Physicochemical and mechanical techniques were carried out to characterize three concrete tyre-rubber waste dosages such as 5,10 and $15 \%, \mathrm{w} / \mathrm{w}$. The elastomeric material was identified as styrene-butadiene rubber (SBR). It was observed that the growing SBR content in the mixture decreased the concrete performance. The best results were presented by $5 \% \mathrm{w} / \mathrm{w}$ tyre-rubber waste concrete sample. This composition was tested at Mourão hydroelectric powerplant spillway as repairing material.
\end{abstract}

Keywords: SBR; tyre-rubber waste; concrete.

\section{INTRODUÇÃO}

As estruturas de concreto devem ser projetadas para operar dentro da vida útil da obra e das especificações de serviço, devendo resistir aos mecanismos de desgaste aos quais estão sujeitas. Em grandes empreendimentos, principalmente, é proeminente e necessário o acompanhamento do seu desempenho e das condições de serviço, a fim de se evitar possíveis danos catastróficos, vindo a comprometer sua segurança e operacionalidade. ${ }^{1}$

Existem obras que estão sujeitas a ações agressivas constantes e, por este motivo, devem ser previstos reparos ao longo de sua vida útil. Como exemplos têm-se as barragens construídas para o aproveitamento hidroelétrico, consumo de água e controle de cheias. Nestes casos, o concreto utilizado está sujeito ao intemperismo natural e ao desgaste superficial, devido à ação química e física da água do reservatório e de outros materiais sólidos arrastados por esta. As principais causas de desgastes superficiais são a cavitação, a abrasão-erosão e os ataques químicos.

A cavitação é normalmente corrigida com alterações de projeto; a abrasão e a erosão são decorrentes tanto da fricção ou atrito de elementos transportados pela água quanto do seu contato em fluxo, devendo o concreto superficial ter características especiais para reduzir o desgaste resultante. Os ataques químicos são causados pela água com alta ou baixa dureza e com a presença ou ausência de constituintes químicos alcalinos e ácidos nela dissolvidos. Assim, praticamente, todo o tipo de água em contato constante ou mesmo sob ciclos de secagem e molhagem intercalados pode ocasionar danos. Nestes exemplos, o poder de dissolução pela água e de reação dos constituintes da pasta de cimento ampliam os defeitos estruturais. A corrosão dos metais da armadura provocada pelo abaixamento

*e-mail: portella@lactec.org.br localizado do $\mathrm{pH}$ do concreto até próximo ou igual a 8,3 é um caso comum originado, principalmente, pelo processo de carbonatação do hidróxido de cálcio ou portlandita presente, a partir do ácido carbônico dissolvido. ${ }^{1,2}$

A dissolução com lixiviação do íon cálcio por outros constituintes da água favorece a diminuição da resistência mecânica do concreto, sendo, normalmente, oriunda da ação dos ácidos orgânicos (húmico, cítrico, fórmico, entre outros) e inorgânicos, destacando-se os ácidos sulfúrico, nítrico e clorídrico. Outros danos gerados a pequenas profundidades das superfícies hidráulicas e ao longo do tempo são as fissuras. Estas podem ser resultantes de expansões químicas causadas pelos álcalis sódio e potássio. Também, por ataque de sulfato e carbonatação, são obtidos produtos de reação, tais como a etringita (3CaO. $\mathrm{Al}_{2} \mathrm{O}_{3} \cdot 3 \mathrm{CaSO}_{4} \cdot 32 \mathrm{H}_{2} \mathrm{O}$ ou na química do cimento $\mathrm{C}_{6} \mathrm{~A} \overline{\mathrm{S}}_{3} \mathrm{H}_{32}$ ) e a taumasita, com composição química $\mathrm{Ca}_{3} \mathrm{Si}(\mathrm{OH})_{6}\left(\mathrm{SO}_{4}\right)\left(\mathrm{CO}_{3}\right) .12 \mathrm{H}_{2} \mathrm{O}$ ou $\mathrm{C}_{3} \mathrm{~S} \overline{\mathrm{S}} \overline{\mathrm{C}} \mathrm{H}_{30}$, respectivamente. ${ }^{2}$

Conhecendo-se a origem do defeito, podem-se especificar materiais de reparo (MR) para as superfícies desgastadas, de forma que sejam adequados à sua característica, bem como às condições operacionais especificadas em projeto.

A utilização de um MR deve ser direcionada para possuir melhores qualidades que o concreto original, ${ }^{1}$ ter custo baixo, boa aderência e baixa permeabilidade para diminuir a ação dos agentes agressivos externos. Deve ser verificada, também, a compatibilidade entre este e o concreto existente. Se os dois sistemas possuem características muito diferentes o MR ou a estrutura circundante fica sujeito a novos danos. Uma dosagem de concreto convencional de mesma formulação daquele utilizado na obra é o mais compatível. No entanto, seu uso como MR pode ser equivocado, uma vez que já esteve suscetível aos agentes agressivos. ${ }^{3}$

O uso de materiais recicláveis em estruturas civis não poderá ter, somente, uma característica ambiental, pelo fato de poder antecipar 
seu descarte se não forem atendidos os preceitos tecnológicos da obra, com melhoria de qualidade e desempenho. ${ }^{4}$

O emprego de concreto com adição de borracha (CAB) é um caso típico de compósito com desempenho melhorado em algumas das propriedades originais, tal como no aumento da capacidade de deformação sem o aparecimento de fissuras. Porém, vem sendo percebida uma diminuição real na resistência mecânica à compressão. ${ }^{4,5}$

Não há um consenso de que as resistências à abrasão de concretos e argamassas sejam ampliadas com a adição de borracha, demonstrando ter desempenho aproximadamente igual ou menor que em dosagens similares de concreto convencional. ${ }^{3-5}$

A utilização de $\mathrm{CAB}$ é também importante do ponto de vista ecológico. O crescimento do descarte de pneus usados vem levando ao limite a capacidade dos aterros sanitários das metrópoles. Há mais de 100 milhões de pneus inservíveis em depósitos oficiais e clandestinos no Brasil. Em 2005, em São Paulo, a quantidade de pneus se aproximou de $3 \%$ do lixo urbano. ${ }^{6}$

A reutilização do pneu inservível pelos processos atuais de fabricação é impraticável economicamente, em virtude das ligações cruzadas provenientes do processo de vulcanização da borracha. Existem alguns métodos de desvulcanização, porém, não são totalmente eficientes por gerarem uma borracha cara e com uso limitado. ${ }^{3,7}$ Alguns setores industriais absorvem parte dos pneus inservíveis, como é o caso das cimenteiras, que os utilizam como combustível em alto-fornos. ${ }^{7}$

O tempo de degradação dos pneus, ao redor dos 150 anos, também dificulta sua estocagem; por isso, há uma resolução nacional designando aos fabricantes e importadores a responsabilidade pela sua destinação final. ${ }^{8}$ A reciclagem, por meio da recapagem ou da remoldagem, aumenta a sua vida útil em cerca de $40 \%$ e diminui o consumo de matéria-prima e de energia. No entanto, este processo gera como resíduo as raspas de borracha. Estas vêm sendo aproveitadas como matéria-prima para várias indústrias paralelas, incluindo a indústria da construção civil, objeto desta pesquisa. Para tanto, considerou-se como estudo de caso a aplicação deste resíduo industrial como MR da superfície do vertedouro da Usina Hidroelétrica Mourão (UHE Mourão).

\section{PARTE EXPERIMENTAL}

\section{Caracterização dos insumos ${ }^{9,10}$}

O aglomerante utilizado foi o cimento Portland composto com adição de pozolana, classe 32, denominado CPII-Z 32. Este material foi caracterizado quanto a sua composição química e resistência mecânica com o tempo. Também, foram caracterizados a distribuição granulométrica, o tempo de pega, a expansibilidade a quente, a massa específica e o índice de finura, todos segundo recomendações de normas.

Como agregado miúdo, foi utilizada areia natural média lavada, sendo testada com o objetivo de verificar e qualificar os materiais de origem, o teor de impurezas e de possibilitar as correções de dosagem.

Pedra brita com dimensão máxima característica de $19 \mathrm{~mm}$ foi adicionada como agregado graúdo, sendo caracterizada previamente por técnicas físico-químicas. Também foi realizada a análise petrográfica para a determinação da sua microestrutura e rocha de origem.

Para propiciar melhor trabalhabilidade ao $\mathrm{CAB}$ foi utilizado um aditivo de origem comercial que é plastificante polifuncional e redutor de água, à base de sais sulfonados. Este aditivo não foi caracterizado em laboratório.

Foram utilizadas raspas de borracha vulcanizada provenientes da indústria de remoldagem de pneus como material substituto ao agregado miúdo. A sua caracterização foi feita por espectrofotometria de infravermelho com transformada de Fourier (FTIR), com o material pulverizado e prensado em pastilhas de $\mathrm{KBr}$, análise no modo de transmitância, em números de onda compreendidos entre 500 e $5000 \mathrm{~cm}^{-1}$, resolução de $4 \mathrm{~cm}^{-1}$ e 21 varreduras/min.

A borracha utilizada não passou por nenhum tipo de tratamento anterior à sua incorporação no concreto. Esta opção foi considerada com base em estudos que propuseram minimizar os custos e simplificar os métodos, já que não foi constatada melhoria na resistência mecânica do $\mathrm{CAB}$, a não ser com o uso de aditivos tipo vinílico, acrílico e de estireno-butadieno. ${ }^{10}$ Mesmo assim, foi identificada pouca evolução no desempenho quanto à aderência entre o MR e o concreto-referência ou convencional, $\mathrm{CR}$.

Água potável foi utilizada para o amassamento da mistura.

\section{Dosagens dos concretos}

Foram dosados os traços do CR e dos concretos com adição de 5\% em peso (p/p), CAB 5; $10 \%$ (p/p), CAB 10; e 15\% (p/p) de borracha, $\mathrm{CAB}$ 15. A incorporação da borracha se deu em relação ao peso do agregado miúdo do $\mathrm{CR}$, e em substituição parcial ao mesmo. A partir destas dosagens foram fabricados os corpos-de-prova (CPs) para os ensaios de resistência ao arrancamento e da resistência à abrasão pelo método submerso e para a caracterização física e mecânica aos 28 dias de cura em câmara úmida.

A consistência dos concretos, expressa pela medida do abatimento de tronco de cone, foi deixada livre, de forma a ser um dos parâmetros variáveis a ser avaliado em função do teor de partículas de borracha.

Os traços dos concretos produzidos encontram-se listados na Tabela 1 .

Tabela 1. Composição dos concretos confeccionados no estudo

\begin{tabular}{lcccccc}
\hline \multirow{2}{*}{ Traços } & \multicolumn{7}{c}{ Consumos $\left(\mathrm{kg} / \mathrm{m}^{3}\right)$} \\
& Cimento & Areia & Brita & Água & Borracha & Aditivo \\
\hline CR & 357 & 722 & 1062 & 179 & 0 & 1,78 \\
CAB 5 & 357 & 686 & 1062 & 179 & 36 & 3,57 \\
CAB 10 & 357 & 650 & 1062 & 179 & 72 & 3,57 \\
CAB 15 & 357 & 614 & 1062 & 179 & 108 & 3,57 \\
\hline
\end{tabular}

\section{Propriedades dos concretos no estado fresco ${ }^{11}$}

A principal propriedade considerada foi a consistência, haja vista que o aumento da incorporação de borracha foi baseado na trabalhabilidade do concreto. O método utilizado foi o de abatimento de tronco de cone.

A massa unitária, de cada dosagem do concreto, foi determinada consecutivamente depois do preenchimento completo de um recipiente de volume conhecido e normalizado.

O teor de ar incorporado foi medido conforme a ABNT NBR NM $47 .{ }^{11}$

Foram moldados CPs cilíndricos de 100 x 200 mm para a medida da resistência à compressão aos 28 dias e das propriedades físicas do concreto (índice de vazios, absorção e massa específica). Os CPs foram desmoldados após 5 dias de cura ambiente.

\section{Propriedades dos concretos no estado endurecido ${ }^{12}$}

As resistências à abrasão submersa e de aderência à tração são características importantes das superfícies hidráulicas. A destruição 
da estrutura do concreto se processa ou pelo rompimento dos grãos dos agregados ou pelo seu arrancamento.

Para a caracterização da resistência à abrasão pelo método submerso e da resistência de aderência, foram utilizados CPs cilíndricos de $300 \times 100 \mathrm{~mm}$. Os moldes foram preenchidos por completo usandose o CR. O seu adensamento foi realizado por vibração de imersão. Após o acabamento superficial e antes do fim de pega, foram feitas 3 cavidades cilíndricas nos CPs com diâmetros e profundidades médios de $50 \mathrm{~mm}$. Estes vazios foram preenchidos com $\mathrm{CAB}$ e o próprio $\mathrm{CR}$ depois da cura úmida do $\mathrm{CP}$.

Para melhor caracterizar o desgaste superficial foram avaliadas as profundidades dos $\mathrm{CPs}$, com paquímetro, a cada $\mathrm{cm}^{2}$ de área correspondente. Os resultados foram apresentados em forma gráfica tridimensional. Também foi verificada a perda de massa resultante.

Os CPs de resistência ao arrancamento tiveram seus vazios preenchidos com apenas um tipo de MR. O adensamento foi realizado com o auxílio de haste metálica e mesa vibratória. Os CPs com vazios superficiais e um exemplo preenchido podem ser vistos na Figura 1.

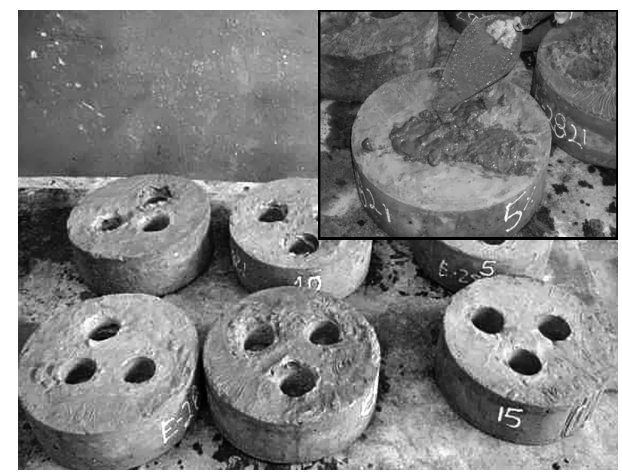

Figura 1. CPs cilíndricos com cavidades; no detalhe, preenchimento com $C A B$

Foi determinada a resistência à compressão axial simples em CPs cilíndricos, aos 3, 7, 28 e 90 dias, conforme ABNT NBR 5739/94. ${ }^{12}$ A realização dos ensaios nas diversas idades permitiu o acompanhamento da evolução das resistências com o avanço do tempo de cura.

Para a determinação das resistências à tração na flexão e por compressão diametral, aos 28 dias, foram utilizados os procedimentos da ABNT NBR 7222/94 e da NBR 12142/92, respectivamente. ${ }^{12}$

O módulo de deformação estático tangente inicial foi obtido segundo a ABNT NBR 8522/84, aos 28 dias. $^{12}$

Para o ensaio de resistência de aderência entre o CR e os CABs foram utilizados CPs semelhantes aos do ensaio de abrasão. Para este estudo cada $\mathrm{CP}$ possuiu 2 traços em análise, sendo um o de $\mathrm{CR}$ e, o outro, um dos traços de CAB. A metodologia foi implementada com adaptações na velocidade de carregamento, no tipo de placa colada na superfície do CP e na sua fixação na máquina de ensaio. ${ }^{10}$ Foram coladas placas metálicas de $50 \mathrm{~mm}$ de diâmetro sobre o MR para acoplar o CP ao dispositivo de ensaio. Neste caso, foi empregada resina epóxi bi-componente com resistência estimada de $60 \mathrm{MPa}$, aos 3 dias. A velocidade de ensaio utilizada foi de $1 \mathrm{~mm} / \mathrm{min}$.

Para a determinação do índice de vazios, massa específica e da absorção de água foram moldados 3 CPs cilíndricos nas dimensões de 100 x 200 mm, sendo testados após 28 dias de cura em câmara úmida. $^{12}$

A micrografia da superfície de fratura do concreto foi obtida por microscopia eletrônica de varredura (MEV) após metalização com ouro, via vaporização catódica ao vácuo. Este teste foi realizado após 28 dias de cura, em equipamento Philips modelo XL 30. Análises químicas elementares semi-quantitativas foram feitas com a microssonda analítica de raios X (espectroscopia de energia dispersiva, EDS) acoplada ao equipamento.

\section{Estudo de caso: UHE Mourão}

Antes da aplicação dos MRs em campo, foram extraídos testemunhos para a avaliação das patologias existentes. A análise foi efetuada por MEV e EDS.

Após, foram recortadas e escarificadas áreas da superfície do vertedouro a uma profundidade média de $50 \mathrm{~mm}$ e com dimensões aproximadas de $750 \mathrm{~mm}$ de lado. Para a aplicação dos MRs foi usada resina epóxi bi-componente como ponte de aderência.

\section{RESULTADOS E DISCUSSÃO}

\section{Patologias do concreto da UHE Mourão}

A análise micrográfica por MEV da superfície de fratura dos CPs da UHE Mourão demonstrou a presença de cristais de etringita e gel de $\mathrm{CaO} \cdot \mathrm{SiO}_{2} \cdot \mathrm{H}_{2} \mathrm{O}(\mathrm{CSH})$, conforme visualizado na Figura 2. A análise por EDS da região do cristal revelou uma composição química elementar semiquantitativa, em porcentagem em peso de $62,6 \%$ de $\mathrm{O} ; 7,1 \%$ de $\mathrm{Al} ; 8,4 \%$ de $\mathrm{S} ; 21,4 \%$ de $\mathrm{Ca}$; e $0,5 \%$ de $\mathrm{C}$. Estes valores e seu respectivo espectro estão em concordância com o encontrado na literatura e, também, com a da composição estequiométrica da etringita pura, que é de $63,8 \%$ para $\mathrm{O} ; 4,3 \%$ para $\mathrm{Al} ; 7,7 \%$ para $\mathrm{S}$ e $19,1 \%$ para Ca. ${ }^{12}$

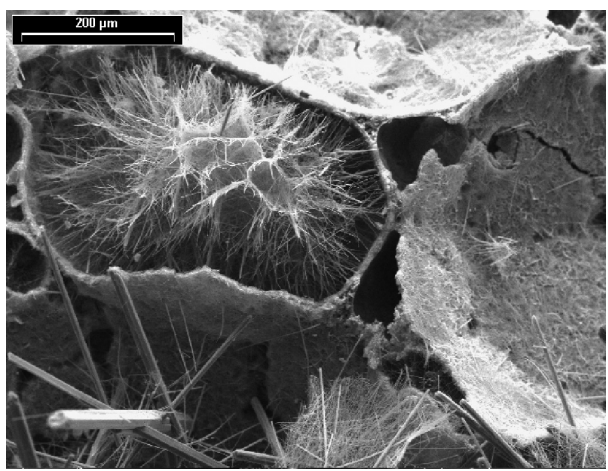

Figura 2. $M E V$ da superficie de fratura de CP extraído da barragem da UHE Mourão com cristais de etringita, $\mathrm{CaCO}_{3}$ e $\mathrm{CSH}$ na forma de "favos de mel"

\section{Caracterização dos insumos}

A composição química do cimento Portland, com exceção do teor de equivalente alcalino, cerca de $30 \%$ acima do especificado (dado pela relação $\mathrm{Na}_{2} \mathrm{O}_{\text {eq }}=\left(\mathrm{Na}_{2} \mathrm{O}+0,658 \mathrm{~K}_{2} \mathrm{O}\right)$ ), ${ }^{2}$ ficou dentro das recomendações de norma. ${ }^{11} \mathrm{Com}$ este teor, tem-se a possibilidade da ocorrência de reações expansivas com agregados reativos. ${ }^{2}$

Os testes químicos e petrográficos realizados no agregado miúdo demonstraram que o mesmo é composto, basicamente, de quartzo tensionado, que é uma fase mineralógica reconhecidamente reativa. ${ }^{13}$ Os resultados obtidos nos ensaios físicos encontraram-se dentro do recomendado, inclusive o da distribuição granulométrica. ${ }^{12}$

A análise petrográfica do agregado graúdo mostrou que o material é formado por riolito originado de rocha ígnea constituída por uma matriz de quartzo-feldspato de granulação fina com fenocristais de feldspato potássico e quartzo. A textura é fanerítica inequigranular portifírica e de estrutura maciça. 
As reatividades potenciais de ambos os agregados foram inócuas com o cimento utilizado, apesar de ter sido identificado um teor não recomendado de álcalis no mesmo. Pode-se inferir que este resultado positivo, pela redução da possibilidade de haver reações químicas expansivas, seja consequiente do teor de pozolana presente no CPII-Z 32 , entre 6 e $14 \%$. ${ }^{9}$

A composição preponderante do resíduo de borracha vulcanizada de pneu foi caracterizada, por intermédio do banco de dados da Bomen (Sadtler, digital libraries, 95-0867), como sendo de borracha de estireno-butadieno (SBR). Seu espectro obtido por FTIR é similar ao do padrão de referência tipo Kraton D-2102.

A distribuição granulométrica apresentada pela borracha está dentro dos limites recomendados para o agregado miúdo natural, conforme pode ser visualizado na Figura $3 .^{12}$

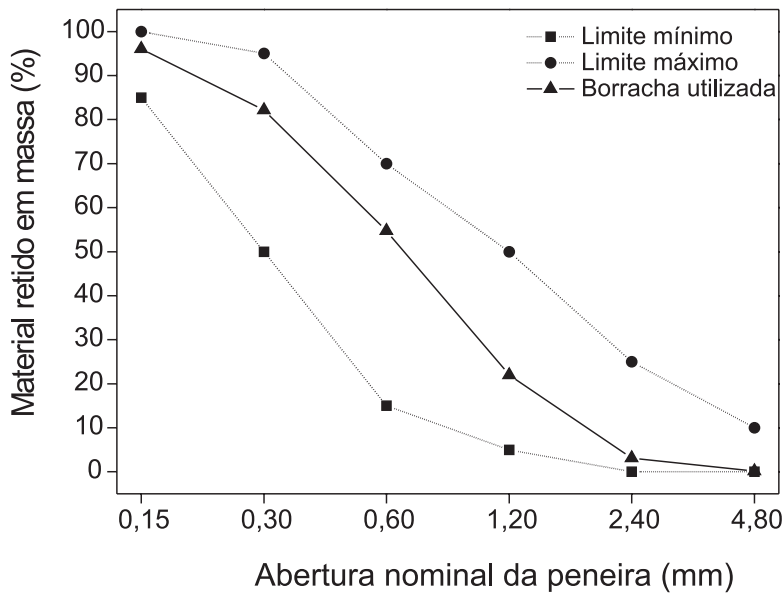

Figura 3. Curva granulométrica do resíduo de borracha usado nos CABs

\section{Dosagens dos concretos}

Quanto aos traços estudados, os resultados apresentados na Tabela 1 demonstraram que houve uma redução gradual na quantidade de agregado miúdo natural (areia), chegando a perto de $15 \%$ em peso $(\mathrm{p} / \mathrm{p})$ com o aumento do teor de borracha até o CAB 15.

Neste caso, foram constatadas as seguintes possibilidades: redução direta do impacto ambiental, por meio da retirada dos pneus inservíveis dispostos inadequadamente; imobilização dos resíduos de borracha em obras que têm vida útil estimada superior a 50 anos, tais como as barragens das usinas hidroelétricas e, preservação indireta do meio ambiente, pela diminuição do volume de extração de areia natural, processo que causa grandes prejuízos à fauna e flora locais.

\section{Propriedades dos concretos no estado fresco}

Os resultados demonstraram haver perdas graduais na trabalhabilidade com o CAB, partindo de $190 \mathrm{~mm}$ no CR; $120 \mathrm{~mm}$ no CAB 5; 23 mm no CAB 10; passando a uma consistência seca e de baixa coesão de $10 \mathrm{~mm}$ para o CAB 15 . Tais resultados podem ser produtos do tipo, forma e quantidade de fibras de borracha adicionadas, necessitando aumentos na relação água/cimento para a manutenção do valor considerado padrão. A massa unitária variou de $2307 \mathrm{~kg}$ / $\mathrm{m}^{3}$ para o $\mathrm{CR}$ para $2157 \mathrm{~kg} / \mathrm{m}^{3}$ para o CAB 15 , representando uma diminuição total em torno de $7 \%$. O ar aprisionado aumentou neste intervalo de dosagem, em média, $152 \%$, respectivamente. Lopes et $a l .{ }^{15}$ verificaram o aumento de $227 \%$ do ar aprisionado pela adição de $5 \%$ de borracha em substituição à areia, em massa.

\section{Propriedades dos concretos no estado endurecido}

A resistência à compressão axial simples dos concretos estudados encontra-se apresentada na Figura 4, em função do teor de borracha adicionada.

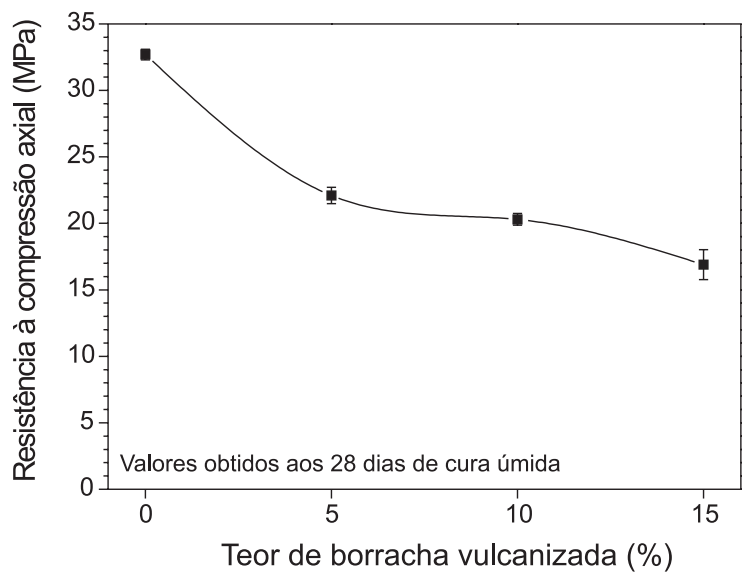

Figura 4. Resistência à compressão axial em função do teor de CAB

A perda de resistência pode estar atribuída ao menor módulo de deformação elástico das partículas de borracha e à menor resistência destas em relação à pasta de cimento e aos agregados. Como a borracha tem maior capacidade de deformação, sua capacidade de resistir aos esforços aplicados fica limitada pela rigidez da matriz de concreto. As partículas de borracha funcionam como vazios no interior da massa de concreto. ${ }^{1,15}$ Também pode estar relacionada a outros fatores, como o aumento do teor de ar aprisionado. Quanto maior o teor de ar aprisionado maior a porosidade e menor a sua resistência. ${ }^{1}$ A perda média resultante para o CAB 15 foi de 48,3\%. Este percentual foi similar ao encontrado na literatura para o CAB 5, confeccionado com borracha na forma de grânulos arredondados. ${ }^{15}$ As fibras de borracha apresentaram melhor comportamento mecânico que os grânulos arredondados.

A resistência à tração na flexão diminuiu cerca de $30 \%$ até o $\mathrm{CAB} 15$, sendo atribuída às diferenças entre os materiais poliméricos e cerâmicos. Neste caso, consideram-se os polímeros como defeitos internos à matriz de concreto. Tal redução pode estar também relacionada ao aumento do teor de ar no concreto. As perdas de resistência à tração por compressão diametral para os CABs 5 e 10, em relação ao $\mathrm{CR}$, foram de 10,5 e $21 \%$, respectivamente. Para o CAB 15 a perda resultante foi de $19,3 \%$. Na Tabela 2, estão mostrados os valores correspondentes.

Foi observada a redução das fissurações em função do aumento do teor de borracha na mistura, sendo necessária a aplicação de um esforço extra para a separação total das faces rompidas. As fibras de borracha mantiveram as duas interfaces unidas, tal como descrito na literatura. ${ }^{5,16,17}$ Atribui-se tal efeito ao menor módulo de elasticidade da borracha e à sua possibilidade de atuar como ponte de transferência

Tabela 2. Resistência à tração dos concretos estudados

\begin{tabular}{lcc}
\hline Traços & $\begin{array}{c}\text { Resistência à tração } \\
\text { na flexão }(\mathrm{MPa})\end{array}$ & $\begin{array}{c}\text { Resistência à tração por } \\
\text { compressão diametral }(\mathrm{MPa})\end{array}$ \\
\hline CR & 4,05 & 2,85 \\
CAB 5 & 3,25 & 2,55 \\
CAB 10 & 2,80 & 2,25 \\
CAB 15 & 2,80 & 2,30 \\
\hline
\end{tabular}


de tensões, iniciando pelo mecanismo elástico seguido pelo de atrito, após fissuração. ${ }^{18}$

O módulo de deformação estático tangente inicial de um concreto depende das características da pasta, dos agregados, das características da zona de interface pasta-agregado e da idade do concreto. ${ }^{1}$ No CAB 5, o módulo baixou 17\% em relação ao CR. Para o CAB 15 esta redução foi de $30 \%$, com um valor final de 23,3 \pm 1,0 GPa.

Os resultados do teste de resistência à abrasão pelo método submerso indicaram desgastes da ordem de $8,6 \mathrm{~mm}$ para o CR; 8,3 $\mathrm{mm}$ para o CAB 5; 6,2 $\mathrm{mm}$ para o $\mathrm{CAB} 10$ e $3,7 \mathrm{~mm}$ para o $\mathrm{CAB}$ 15 , respectivamente.

No CR ocorreu o desgaste da pasta até a superfície da brita, sendo que alguns agregados foram arrancados. Na região preenchida com $\mathrm{CAB}$ este desgaste não foi tão intenso. $\mathrm{A}$ argamassa permaneceu envolvendo parte da superfície do agregado graúdo após o ensaio.

O CAB 15 apresentou o menor desgaste resultante entre os 4 traços presentes. Pode-se inferir que tal desempenho tenha sido conseqüente do próprio teor de borracha na mistura, uma vez que foi observada melhoria de desempenho deste parâmetro com o aumento da concentração da mesma nas dosagens. Na Figura 5, está mostrada a imagem da superfície de um dos CPs resultantes do ensaio.

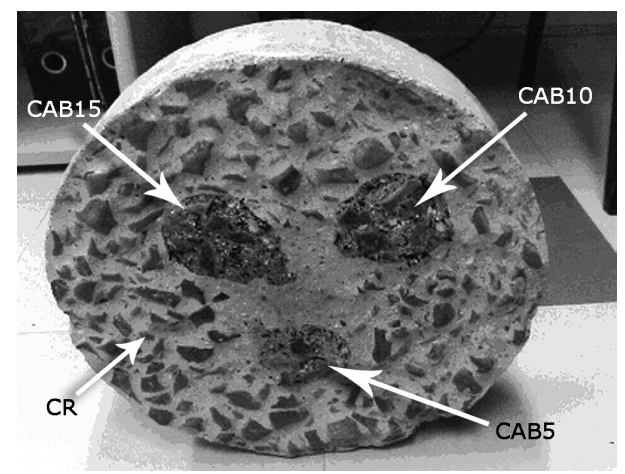

Figura 5. Imagem do desgaste do CR com CAB 5, 10 e 15, após o teste de abrasão

Os valores médios da resistência de aderência pelo método de tração na superfície entre o $\mathrm{CR}$ e o $\mathrm{CAB}$ foram de, aproximadamente: 4,5 MPa no CR; 4,9 MPa no CAB 5; 1,3 MPa no CAB 10 e 1,9 MPa, no CAB 15. Mesmo com a redução obtida, pode-se considerar que tais valores corroboraram com um MR de boa compatibilidade com o CR. ${ }^{3}$

Quanto ao teor de absorção de água por imersão, após saturação e fervura dos CPs, verificou-se a diminuição dos valores com o aumento do teor de resíduo. Os resultados verificados para o $\mathrm{CR}, \mathrm{CAB} 5, \mathrm{CAB} 10 \mathrm{e}$ CAB 15 foram de 5,1; 4,2; 3,8 e 3,4\%, respectivamente. Com isso, todos os traços estudados apresentaram resultados inferiores ao limite máximo recomendado em norma para concretos estruturais, que é de $6 \%{ }^{11}$

As micrografias, obtidas por $\mathrm{MEV}$, das superfícies de fratura de CPs com CAB mostraram quantidades crescentes de poros com o aumento do teor de borracha na mistura, o que confirma o índice de ar incorporado medido no concreto fresco. Na Figura 6, podem ser observados poros espalhados aleatoriamente e fibras de borracha (indicadas por setas) que podem ter sido arrancadas ou rompidas na superfície de fratura do $\mathrm{CAB} 15$.

\section{Propriedades dos MRs aplicados}

As patologias indicaram a necessidade de um maior rigor na escarificação e limpeza do local, bem como a aplicação da ponte de aderência à base de resina epóxi anterior à aplicação dos MRs. Esta, além de ter bom desempenho mecânico pode criar uma interface capaz de dimi-

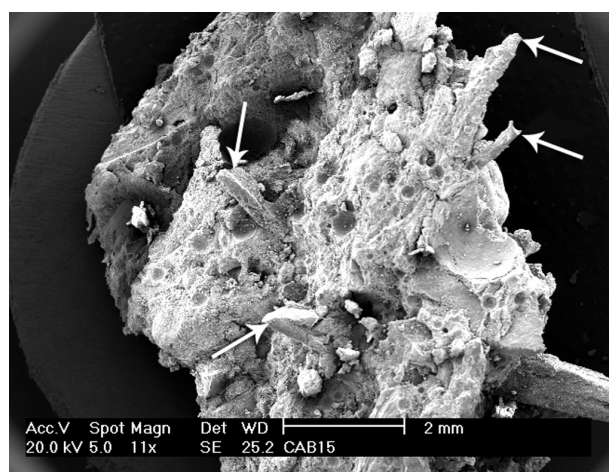

Figura 6. Micrografia, por MEV, da superfície de fratura do CAB 15. As setas indicam as fibras de borracha

nuir tanto a permeabilidade quanto os efeitos da reatividade química observada no local abaixo do MR, aumentando sua vida útil.

Para a aplicação em campo foi considerado o CAB 5 como o de melhor desempenho. Esta dosagem foi facilmente moldada mesmo na superfície inclinada da superfície do vertedouro da UHE Mourão. O acabamento foi bem sucedido e sem problemas operacionais. O seu desempenho em campo vem sendo monitorado em função do tempo.

\section{CONCLUSÕES}

A adição do resíduo de borracha em substituição à massa de areia no concreto fresco diminuiu a trabalhabilidade do concreto resultante, tendo sido atribuído tal fator à borracha na forma de fibras e quantidades adicionadas. Também, foram observados redução na massa unitária e aumento no teor de ar aprisionado.

Ocorreram perdas na resistência mecânica à compressão de até $48,3 \%$ para o CAB 15 , cujo valor médio resultante foi de $16,9 \pm 1,1$ $\mathrm{MPa}$. Para o uso em superfície hidráulica de barragem foi considerado o CAB 5, com 22,1 $\pm 0,6 \mathrm{MPa}$.

$\mathrm{O}$ resultado da resistência à tração na flexão diminuiu cerca de $30 \%$ até o CAB 15, trazendo, como vantagem, uma redução na fissuração resultante com necessidade de aplicação de um esforço extra para a sua ruptura total. As fibras de borracha mantiveram as duas interfaces unidas após a ruptura.

Os desgastes abrasivos, medidos nos sistemas com CAB, ficaram menores que o do próprio $\mathrm{CR}$. Pode-se inferir que a adição da borracha trouxe melhoria no desempenho final do concreto, sendo recomendado para uso como MR em superfícies hidráulicas.

Os valores médios da resistência de aderência reduziram de 4,5 MPa no CR para 1,9 MPa com o CAB 15. Mesmo assim, tais valores indicaram a boa compatibilidade entre o MR e o CR. ${ }^{5} \mathrm{O}$ valor médio obtido para o CAB 5 foi de 4,84 MPa, portanto, superior ao do próprio CR.

$\mathrm{O}$ uso do $\mathrm{CAB} 5$ pode trazer como vantagens adicionais, as reduções: do impacto ambiental, pela retirada dos pneus inservíveis depositados no meio ambiente e pela sua imobilização direta a tempos superiores a 50 anos (expectativa de vida útil de barragens); da emissão de até $100 \mathrm{~kg}$ de $\mathrm{CO}_{2} \cdot \mathrm{m}^{-3}$ de concreto, ao meio ambiente ${ }^{14} \mathrm{e}$, do consumo dos agregados graúdos e miúdos, cuja extração é grande causadora de impactos ambientais.

\section{AGRADECIMENTOS}

À CAPES, pelas bolsas de Mestrado e Doutorado; à UFPR/PIPE; ao CNPq, pelos subsídios da Lei 8010/90, L.I. 06/1020664-5 e pelas bolsas PIBITI; à COPEL, ao LACTEC e à ANEEL, pelo suporte financeiro e infra-estrutura. 


\section{REFERÊNCIAS}

1. Neville, A. M.; Propriedades do Concreto, $2^{\text {a }}$ ed., Pini: São Paulo, 1997.

2. Taylor, H. F. W.; Cement Chemistry, Academic Press: London, 1990.

3. American Concrete Institute; Concrete Repair Manual, $1^{\text {st }}$ ed., ACI International: Farmington Hills, 1999.

4. Segre, N.; Tese de Doutorado, Universidade Estadual de Campinas, Brasil, 1999.

5. Topçu, I. B.; Cem. Concr. Res. 1995, 2, 304; Topçu, I. B.; Cem. Concr. Res. 1997, 2, 177; Topçu, I. B.; Avcular, N.; Cem. Concr. Res. 1997, 12 , 1893.

6. Gomes Filho, C. V.; Dissertação de Mestrado, Instituto de Tecnologia para o Desenvolvimento, Brasil, 2007; http://www.cempre.org.br/ fichas_tecnicas_pneus.php, acessada em Novembro 2006.

7. Kamimura, E.; Dissertação de Mestrado, Universidade Federal de Santa Catarina, Brasil, 2002.

8. ht tp://www.mma.gov.br/port/conama/legiano 1 . $\mathrm{cfm}$ ?codlegitipo $=3 \&$ ano=1999, acessada em Maio 2005 .

9. Associação Brasileira de Normas Técnicas; NBR 5743, Rio de Janeiro, 1989; NBR 5744, Rio de Janeiro, 1989; NBR 5745, Rio de Janeiro, 1989; NBR 5747, Rio de Janeiro, 1989; NBR 7227, Rio de Janeiro, 1989; NBR 9203, Rio de Janeiro, 1985; NBR 8347, Rio de Janeiro, 1986; NBR 1579, Rio de Janeiro, 1991; NBR 11581, Rio de Janeiro, 1986; NBR 11578, Rio de Janeiro, 1991; NBR 11582, Rio de Janeiro, 1986; NBR NM 23, Rio de Janeiro, 2001; NBR NM 76, Rio de Janeiro, 1998; NBR NM 248, Rio de Janeiro, 2003; NBR 7218, Rio de Janeiro, 1974; NBR 7219, Rio de Janeiro, 1987; NBR 7220, Rio de Janeiro, 1976; NBR 9776, Rio de Janeiro, 1977; NBR NM 30, Rio de Janeiro,
2001; NBR 9937, Rio de Janeiro, 1987; NBR NM 248, Rio de Janeiro, 2003.

10. Li, G.; Garrick, G.; Eggers, J.; Abadie, C.; Stubblefield, M. A.; Pang, S. S.; Compos. B. Eng. 2004, 35, 305.

11. Associação Brasileira de Normas Técnicas; NBR NM 67, Rio de Janeiro, 1998; NBR NM 47, Rio de Janeiro, 2002; NBR 5738, Rio de Janeiro, 1994; NBR 6124, Rio de Janeiro, 1980.

12. American Society for Testing and Materials; ASTM C 1138 , West Conshohocken, 1997; Freitas, C.; Dissertação de Mestrado, Universidade Federal do Paraná, Brasil, 2007; Associação Brasileira de Normas Técnicas; NBR 5739, Rio de Janeiro, 1994; NBR 7211, Rio de Janeiro, 2005; NBR 7222, Rio de Janeiro, 1994; NBR 12142, Rio de Janeiro, 1992; NBR 12142, Rio de Janeiro, 1992; NBR 13528, Rio de Janeiro, 1995; NBR 9778, Rio de Janeiro, 1987; NBR 8522, Rio de Janeiro, 1984; Famy C.; Taylor, H. F. W.; ACI Mat. J. 2001, 98, 350; Böke, H.; Akkurt, S.; Cem. Concr. Res. 2003, 33, 1457.

13. Hasparik, N. P.; Dissertação de Mestrado, Universidade Federal de Goiás, Brasil, 1999.

14. http://www.sigma-foco.scire.coppe.ufrj.br/UFRJ/SIGMA/jornadaIC/ publicacao_foco/trabalhos/consulta/relatorio.stm?app=jic_publicacao_t rabalho\&ano $=2007 \&$ codigo $=2470 \&$ buscas_cruzadas $=\mathrm{ON}$, acessada $\mathrm{em}$ Fevereiro 2008

15. Lopes, M. D.; Marques, A. C.; Ricci, E. C.; Fioriti, C. F.; Akasaki, J. L.; Anais do $47^{\circ}$ Congresso Brasileiro do Concreto, Recife, Brasil, 2005.

16. Turatsinze, A.; Bonnet, S.; Granju, J. L.; Build. Environ. 2005, 40 , 221.

17. Martins, I. R. F.; Dissertação de Mestrado, Universidade Estadual Paulista, Brasil, 2005.

18. Nunes, N. L.; Agopyan, V.; Boletim Técnico, EDUSP: Brasil, 1998. 